\title{
ABERRANT SUBCAUDAL SQUAMATION ON A SPECIMEN OF THE BULL SNAKE
}

by George B. Pendlebury, 203, 820 - 5th Ave. S.W., Calgary, Alberta

Subcaudal squamation on the bull snake Pituophis melanoleucus sayi normally consists of a series of paired scales. A specimen with anomalous squamation was found by $\mathrm{Mr}$. W. E. McKay, Director of the Calgary Zoo, on the Trans-Canada Highway $16 \mathrm{~km}$ east of Tilley, Alberta, on August 20, 1972.

The specimen (GBP-72-2), is an adult male with a snout to vent length of $881 \mathrm{~mm}$ and a total length of 1032 $\mathrm{mm}$. Immediately posterior to the vent there are a pair of subcaudals that have failed to meet medially. The resulting space is occupied by a small third scale. These scales are followed by five single subcaudals (Fig. 1).

In order to verify that it is the squamation and not the location of the vent that is anomalous, the specimen was X-rayed to locate the position of the cloaca with respect to the internal structure. X-ray photographs reveal that the structure-vent relationship is normal (Fig. 2), and that the scales do constitute the anomaly.

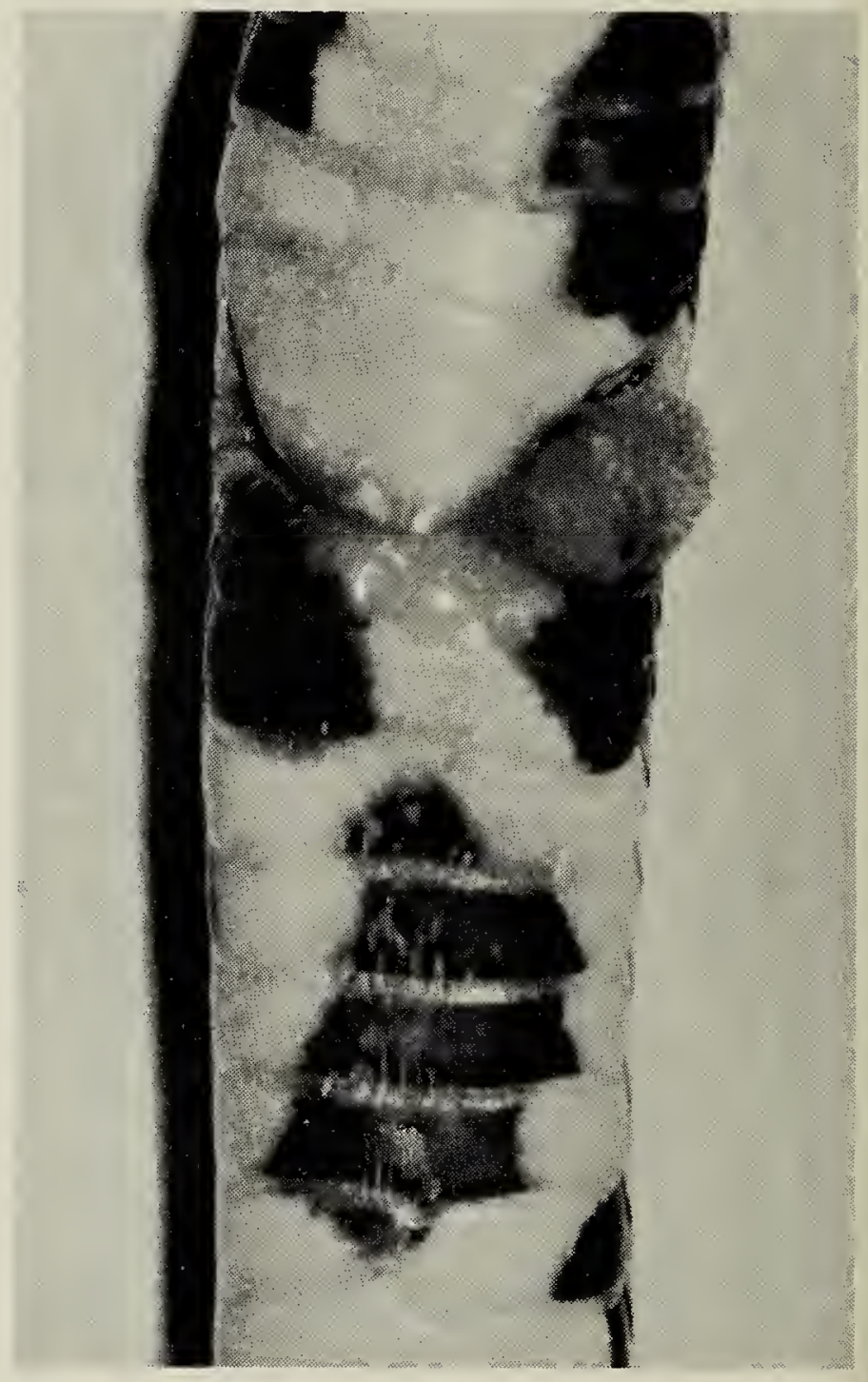

Fig. 1. Ventral view of a portion of Pituophis melanoleucus sayi showing vent, partially everted hemipenis and aberrant subcaudal squamation.

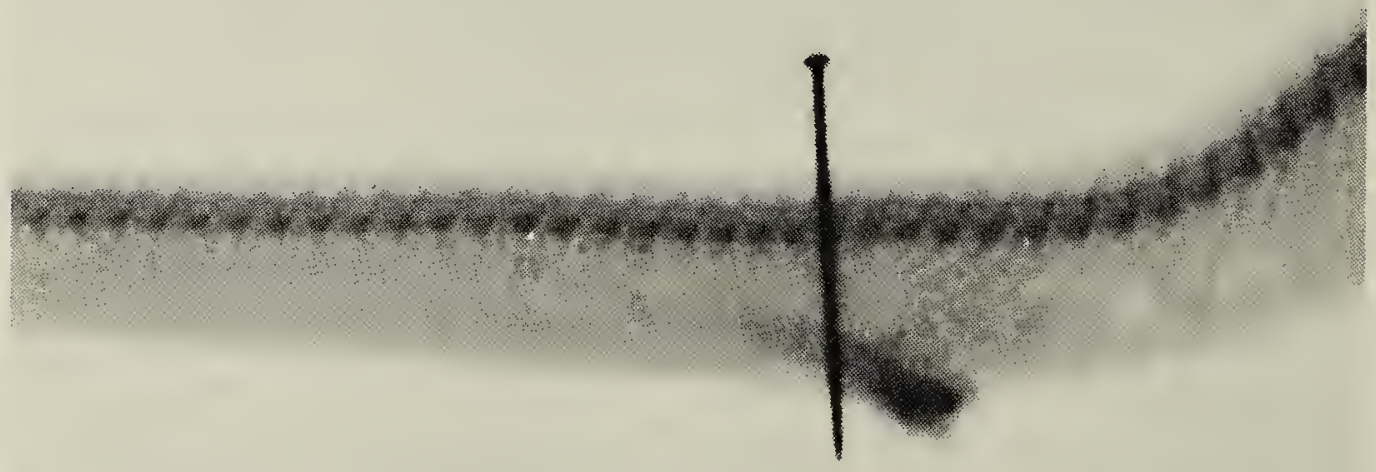

X-ray photo by Cheryl Pendlebury

Fig. 2. X-ray photograph of Pituophis melanoleucus sayi with aberrant subcaudal squamation The pin marks the posterior margin of the anal plate. Shot at $1 / 10$ sec., 100 ma., and $40 \mathrm{kvp}$ on a Picker 200 ma. X-ray machine. 